\title{
MAPPING OF SOIL QUALITY AND SENSITIVITY TO DEGRADATION BY ADAPTING THE MEDALUS METHOD IN THE STEPPE ZONE OF THE WILAYA OF SAIDA (ALGERIA)
}

\author{
ZAIDI Hachemi ${ }^{1,2 *}$, AZZAOUI Mohamed Essalah ${ }^{3}$, SOUDANI Leila ${ }^{3}$, \\ MAATOUG Mhamed ${ }^{3}$, BOUZIANE Salim ${ }^{4}$ \\ ${ }^{\text {I*Higher Agronomic School of Mostaganem, Algeria; }}$ \\ ${ }^{2 *}$ University of Mostaganem, Laboratory of Biodiversity and Conservation of Water and Soil, Algeria; \\ ${ }^{3}$ University of Tiaret, Laboratory of Agro-Biotechnology and Nutrition in Semi-Arid Zones, Faculty of Natural and \\ Life Sciences, Algeria; \\ ${ }^{4}$ Ibn Khaldoun University, Tiaret, Algeria;
}

"Corresponding Author ZAIDI Hachemi, e-mail: Zaidi.hachemi@ yahoo.fr; Received March 2021; Accepted April 2021; Published May 2021; DOI: $\underline{\text { https://doi.org/10.31407/ijees11.313 }}$

\begin{abstract}
The steppe plains of Saida (Algeria) has an interest in the agricultural economy that is privileged in extensive area for sheep breeding. Due to the extensive sheep farming, it resulted with a severe degradation. In this phenomenon, by inaugurating the direct consequence of the combined action of man and climate, the recurrent drought and the increasing anthropogenic pressure affect the soil which is the main factor in the ground and the production of biomass, particularly in semi-arid area and the arid ones. By applying the MEDALUS (The Mediterranean Desertification and Land Use) that is mainly based on the investigation of the physical, biological, and socioeconomic processes in this current work that will affect the evaluation of the sensitivity of the soils to the process of desertification. It is a cartography based on the combination of several types of sounds like the textural triangle USDA (United States Department of Agriculture), soil map, geological map, MNT and satellite images. The soil quality index are the basis of the mentioned method which determine the resistance to the phenomenon of desertification. These qualities are essential and can be assessed using simple soil properties such as soil texture, soil depth, parent materials, slopes and soil stoniness's, and soil morpho-pedological. This resultant has been obtained, and will be initiated after the final validation, a new decision-making aid reference for the sustainable management of steppe zones. The resulting soil sensitivity map to desertification processes includes three MEDALUS nomenclature classes: class of fragile soils, moderately sensitive soils and soils that aren't too sensitive to desertification with dominance of fragile areas on the zone.
\end{abstract}

Keywords: steppe plains, desertification, MEDALUS, arid zones, Saida. 